\title{
Research
}

\section{Linking Ecological and Perceptual Assessments for Environmental Management: a Coral Reef Case Study}

\author{
$\underline{\text { Elizabeth A. Dinsdale }}^{1}$
}

\begin{abstract}
Integrating information from a range of community members in environmental management provides a more complete assessment of the problem and a diversification of management options, but is difficult to achieve. To investigate the relationship between different environmental interpretations, I compared three distinct measures of anchor damage on coral reefs: ecological measures, perceptual meanings, and subjective health judgments. The ecological measures identified an increase in the number of overturned corals and a reduction in coral cover, the perceptual meanings identified a loss of visual quality, and the health judgments identified a reduction in the health of the coral reef sites associated with high levels of anchoring. Combining the perceptual meanings and health judgments identified that the judgment of environmental health was a key feature that both scientific and lay participants used to describe the environment. Some participants in the survey were familiar with the coral reef environment, and others were not. However, they provided consistent judgment of a healthy coral reef, suggesting that these judgments were not linked to present-day experiences. By combining subjective judgments and ecological measures, the point at which the environment is deemed to lose visual quality was identified; for these coral reefs, if the level of damage rose above $10.3 \%$ and the cover of branching corals dropped below $17.1 \%$, the reefs were described as unhealthy. Therefore, by combining the information, a management agency can involve the community in identifying when remedial action is required or when management policies are effectively maintaining a healthy ecosystem.
\end{abstract}

Key Words: Coral reefs; perceptual meanings; social-ecological assessments

\section{INTRODUCTION}

Managing the environment involves many people. Each person brings to the management process a different view and way of describing the environment. The relationship between these views and how they are linked remains an outstanding question. Although policy makers recognize the need to include the human dimension in environmental management (Gunderson et al. 1995, Endter-Wada et al. 1998), the linking of knowledge from the nature science, social science, and local communities is problematic (Policansky 1998, Bellamy et al. 1999, Hull et al. 2003, Failing et al. 2004, Fryirs and Brierley 2009). Generally, there is delineation in the types of information that different people bring to the process. Local communities are often asked how they use an environment, whereas natural scientists are asked to quantify the presence of different organisms in the environment and social scientists are asked to describe an economic or social value for the environment, e.g., the rezoning of the Great Barrier Reef in 2003 (Hutchings 2004). These delineations have occurred because of the historic way in which natural and social sciences were conducted.

Science was conducted from a positivist viewpoint in which the environment was considered separate from social practices and human experiences, thus providing unambiguous, observable, and rectifiable outcomes (Macnaghten and Urry 1998, Robertson and Hull 2001, Song and M'Gonigle 2001, Tress 2002). Natural sciences were considered the basis for describing environmental condition (Lele and Norgaard 1996). Information from communities about the environment or local ecological knowledge is experiential, gained by continual observation and constructed on the basis of community values and beliefs (McNeely 1995, 
Burroughs 1999, Berkes and Folke 2000, Olsson and Folke 2001, Cousins et al. 2009). Local knowledge has a strong cultural component, is often revealed in stories, myths, or events, and, until recently, was not used in management processes. Now multiple interpretations of the environment are being recognized (Holling et al. 2000). Local communities possess detailed knowledge of local environmental conditions (Olsson and Folke 2001), but bringing that information into the environmental management process is difficult (O'Flaherty et al. 2008).

Local communities develop practices that are adapted to the local ecology and can suggest innovative practices for environmental management. The use of local knowledge has the potential to develop a range of management practices to diversify environmental policy (Brock and Carpenter 2007). The involvement of communities in management process empowers the community, which increases the likelihood of success. Combining scientific and local knowledge has been useful in rehabilitation projects (Olsson and Folke 2001, Failing et al. 2004), discerning test values for adaptive management strategies (MacKinson 2001), and defining fish population dynamics (Ross et al. 1997, Slocombe 1998, Robertson et al. 2000, Ura 2003). Modern management strives for full participation in management decisions, i.e., experts and nonexperts engage in public negotiations. To achieve an integrated management outcome, information from multiple parties is not only considered, but views are related and used in the process.

Environmental information can be expressed in multiple ways, including environmental quantification, perceptual meanings, and normative judgments. In environmental quantification, an aspect of the environment is identified, normally by scientists, and a method is constructed to obtain an estimate of the level of that aspect in each environment (Done 1995). Perceptual meanings are descriptions of important elements within the environment identified by the viewer with no direct quantification (Dinsdale and Fenton 2006). Normative judgments are descriptions made of the environment using a term that has a community meaning, such as "health." The ecosystem health concept (Burroughs 1999, Huntington et al. 2002), which is widely used in environmental management, is based on this normative judgment. Whether there is a relationship between these three types of measures of the coral reef environment and whether people use a set of environmental cues or indicators to judge the environment are questions that will be examined in this investigation.

To compare the relationship between various measures of the environment, coral reefs were used as a case study. Coral reefs are complex, productive, and highly valued environments (Best and Bornbusch 2001), making them an ideal environment in which to conduct this study. The high levels of boating plus the damage from the associated anchoring was one area of concern for managers, local residents, and scientists in the Whitsundays region of the Great Barrier Reef (Malcolm 1998, GBRMPA 1999, 2009, Harriott 2002). Coral reefs are subject to multiple stressors and have strategies to survive physical damage (Marshall 2000a,b). This therefore leads to uncertainty as to the amount of damage being caused by anchoring as opposed to other causes. To identify appropriate environmental cues or indicators to describe the changes associated with anchoring, two assessments of the region were conducted: (1) an ecological assessment, which determined that the levels of branching corals, soft corals, and damage varied between sites with high and low anchoring (Dinsdale and Harriott 2004), and (2) a perceptual survey, which identified three major perceptual meanings people used to describe the coral reef environment. The first perceptual meaning, which explained $31.176 \%$ of the variation, was an evaluative dimension; the second perceptual meaning, which explained $11.476 \%$ of the variance, was an activity dimension; and the third perceptual meaning, which explained $7.6 \%$ of the variation, was a diversity dimension. These dimensions were consistent between scientists and lay participants. The combination of these three dimensions distinguishes between coral reefs with high and low anchoring (Dinsdale and Fenton 2006). These two studies provide some of the data needed to make the comparison between the three measures.

The first objective of the current research was to compare perceptual meanings with normative health judgment to identify whether "health" is a concept that people apply to the coral reef environment. Using descriptions provided by two groups of people, those with and without a working association with coral reefs, the consistency between the views of these two groups regarding the health of the coral reef environment can be assessed. The second objective of the research was 
to compare across the three measures to determine which indicator or environmental cue people were using to make the health judgment. This will be achieved by comparing the ecological measures and perceptual meanings with the health judgments. If different people within the community view the environment in a similar way or use similar cues, these can be identified and used in management discussions. The comparison between the health of the environment and the ecological measures will identify how much change in the environmental cue can occur before the environment is perceived to have lost its value or health.

\section{METHODS}

\section{Overview}

The three individual measures were collected by conducting a series of analyses on photographs taken from six coral reefs: three coral reefs associated with high levels of anchoring and three reefs associated with low levels of anchoring. On each of the reefs, two depths were surveyed: the crest $(3 \mathrm{~m})$ and the lower slope $(9-11 \mathrm{~m})$. A full description of the sites is provided in Dinsdale and Harriott (2004). Ecological measures were obtained using the grid point method, perceptual meanings were obtained using a repertory grid method, and health judgments were obtained using a researcherdefined survey (Fig. 1). Comparisons between the measures were conducted using a regression tree analysis.

\section{Assessments of coral reefs using the three individual measures}

\section{Ecological measures}

The photographs of the coral reef sites were taken along a transect line to obtain a total of 26 photographs from the six sites. A side view of the coral reef was taken because it gave a more familiar appearance to the reef compared to a photograph taken looking down at the reef structure. Because the quality of underwater photographs is affected by the weather, tide, and time of day, photographs were taken during comparable environmental conditions between March and May 2002. A 2-cm² grid was overlaid on each of the 26 photographs, providing 126 points that could be used to quantify the ecological elements.

First, the number of points associated with the three broad categories of "water," "background," and "foreground" were measured to ensure that the photographs had a standardized layout. The category "water" is self-evident. The category "background" was the portion of the coral reef that could not be identified because of the integrity of the photograph, e.g., shading by other components or distance. The "foreground" comprised coral reef components that were readily identified. The three categories were similar for photographs from each site-depth combination. Photographs comprised on average $65.3 \pm 3.6 \%$ foreground, $14.4 \pm 3.2 \%$ background, and $20.3 \pm 4.4 \%$ water, suggesting a standardized layout of the components in the photographs. Second, the foreground area of the photographs was further surveyed. The percent cover of the coral reef structure underlying each point was recorded for five components: (1) branching corals, (2) massive hard corals, (3) soft corals, (4) damage, and (5) fish. The variation between the ecological measures of the coral reefs with high and low levels of anchoring was identified using a multiple analysis of variance.

\section{Perceptual meanings}

The perceptual meanings were obtained using a modified repertory grid survey (Dinsdale and Fenton 2006). This type of survey elicits personal descriptions of the environment. There are no researcher-defined terms used in the survey, and therefore they are a representation of people's knowledge or thoughts about the environment. In repertory grid surveys, participants are asked to describe in their own words the difference between the 13 pairs of photographs. The photographs are then rated by the participants for each of the descriptors they provide, and a principal component analysis is conducted to identify the meanings prescribed to the environment. Participants in the perceptual study were separated into two groups: participants in group 1 had a working association with coral reefs, that is, their occupation involved a level of interaction with coral reef environments, whereas participants in group 2 had no such association and some had never visited a reef. The responses from the two participant groups are presented separately. Although some participants lived near the Whitsundays, other participants had 
Fig. 1. An outline of the method used to link the ecological measures, perceptual meanings, and health judgments of coral reefs associated with high and low intensities of anchoring.

Question: Do different community groups judge changes in coral reef condition similarly?

Measure 3: Normative judgment of health
Environment:

Coral reefs

- 3 reefs with high anchoring

- 3 reefs with low anchoring

Photographs

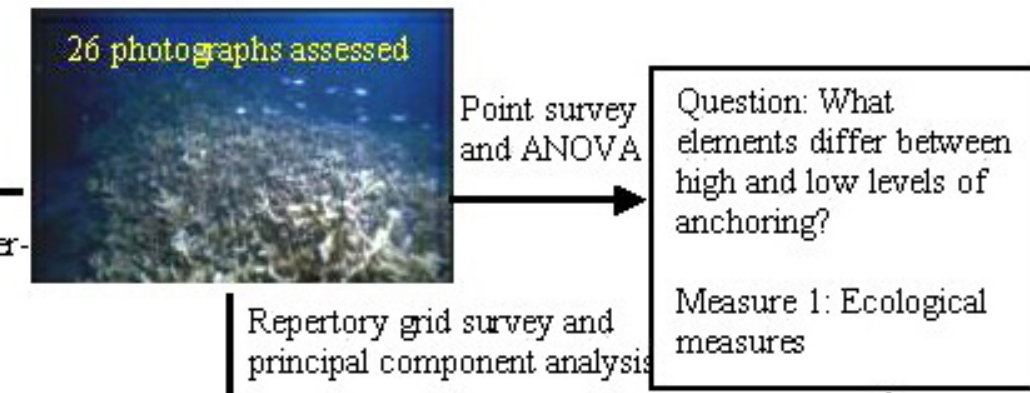

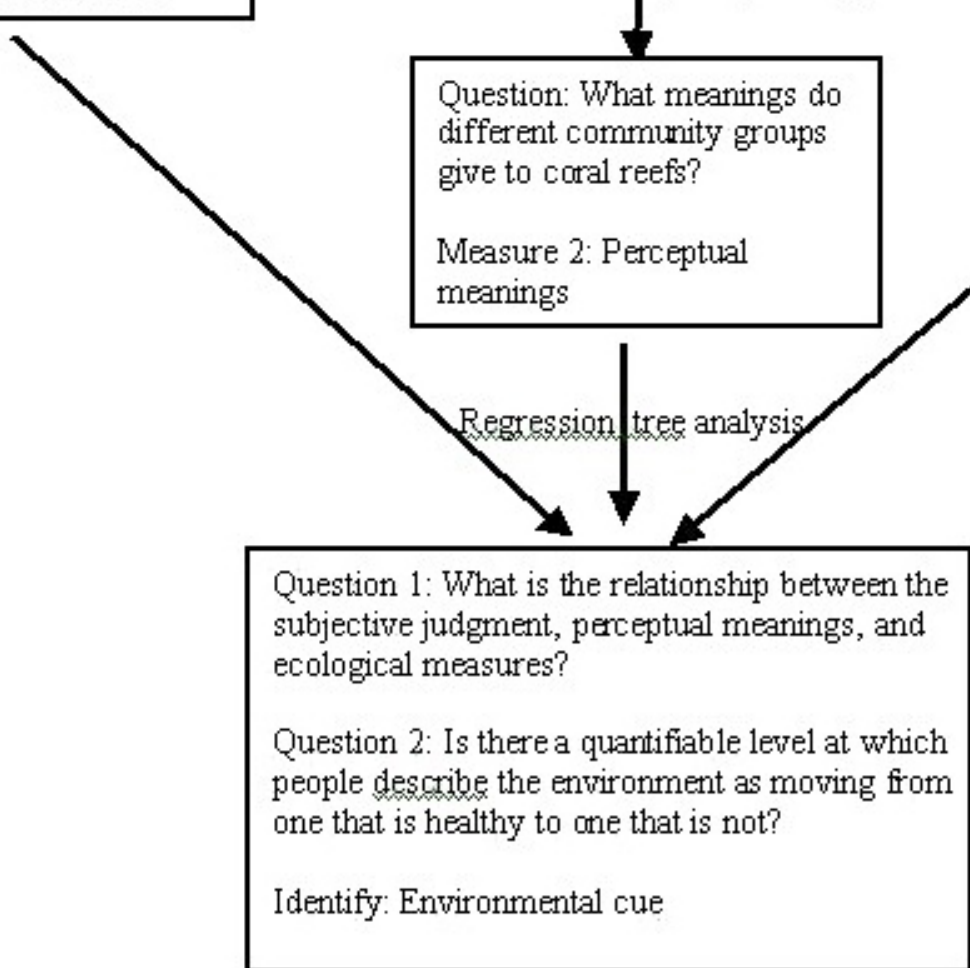


never visited the study location or any coral reef. This survey was conducted in 2005, and the analysis was presented in Dinsdale and Fenton (2006). The results are used here to enable the comparison between perceptual meanings, ecological measures, and health judgments.

\section{Health judgments}

To obtain the health measures, the participants were asked to judge on a scale of 1 to 6 , in which 1 was unhealthy and 6 was healthy, the health of the coral reefs depicted in each of the 26 photographs. The judgments provided by the two participant groups were used to obtain an estimate of the health of coral reefs associated with different levels of anchoring intensity. An analysis of variance was conducted on the health ratings with high and low anchoring intensity and coral reef sites as fixed factors. The health judgments provided by the two participant groups were analyzed separately. Coral reef sites were nested within the anchoring treatments, and the interaction terms were not tested because the sampling design was not fully orthogonal. The survey was constructed so that the question about the health of the reef only became obvious at the end of the survey, and therefore in some cases was not answered by the participants. The survey was constructed in this way to reduce a potential bias when the participants were providing the perceptual meanings.

Of the 42 participants in group 1,32 provided usable health judgments, as did 28 participants from the 34 in group 2. A reliability analysis was conducted to determine whether participants were judging the health of the photographs in a consistent manner. The concept of reliability refers to the average accuracy of the estimates of the scores. The Alpha Model was used to identify internal consistency based on the average of inter-item correlation. The item here was the health ranking given by each person to each photograph, i.e., testing whether there was consistency in the way people were judging the health of each photograph.

\section{Analysis of the relationship between perceptual meanings and health judgments}

To determine whether a relationship existed between the perceptual meanings and health judgments, multiple linear regressions were used. It was hypothesized that, if a judgment of the health of the environment was an inherent judgment, i.e., one that people use on an everyday basis, there should be a correlation between these health judgments and the perceptual meanings used to describe coral reefs. The three perceptual meanings, i.e., evaluation, activity, and diversity, were used as predictive variables and regressed against the mean health ratings from the two participant groups. Predictive variables were entered into the models in a stepwise fashion to identify the most important predictor(s) of the health judgments, i.e., the predictor that explained the highest amount of variance in the health rating. Assumptions of normality and heterogeneity were met by all the variables in the analysis.

\section{Analysis to identify environmental cues}

A regression tree analysis was conducted to identify the indicators or environmental cues that were consistent with the description of a healthy coral reef. The evaluation dimension provided a more accurate description of health because it was an elicited dimension, not one constrained by a term that the researcher provided to participants. The multiple linear regression analysis conducted in the previous section revealed a near perfect relationship between the evaluation dimension and health judgments. Thus, the evaluation dimension was used as the health measure for the regression tree analysis.

A regression tree analysis splits the data into mutually exclusive groups that are as homogeneous as possible (De'ath 2002). The final groupings are characterized by a mean value of the response variable, i.e., the analysis divides the photographs into groups that are rated similarly for health or evaluation. The response variable for the regression tree analysis was the evaluation dimension. The predictive variables were the five ecological measures (percent cover of damage; soft, branching, and massive corals; and fish) and the two remaining perceptual meanings, i.e., the activity and diversity dimensions. The predictive variable that was the most important in each of the resultant groups is identified on the branches of the tree, and the amount of variance explained by each split in the tree is represented graphically by the relative lengths of the vertical lines associated with each split. The number of splits in the tree is identified by a crossvalidation technique (De'ath and Fabricius 2000). Cross-validation provides an estimate of the 
prediction error for trees of a given size. Using a plot of the relative error, the best tree size is the smallest tree, such that its estimated error rate is within one standard error of the minimum. The information provided by the two participant groups was tested in two separate regression-tree analyses.

\section{RESULTS}

\section{Assessments of coral reefs using the three measures}

The three types of descriptions of coral reef condition, i.e., the ecological measures, perceptual meanings, and health judgments, all identified a difference between the coral reefs associated with high and low intensities of anchoring (Figs. 2-4). The ecological measures identified higher coverage of soft corals at sites with low anchoring intensities and higher coral damage at sites with high anchoring intensities (Fig. 2). The perceptual meanings placed coral reef photographs associated with low anchoring intensities toward the "good" end of the evaluation dimension. In contrast, photographs from high anchoring sites were evaluated as "poor" (Fig. 3). Although photographs from sites with both high and low levels of anchoring intensity had a range of perceived activity, slightly higher activity was identified at sites with lower levels of anchoring intensity (Fig. 3).

The judgments of health from the two participant groups showed a difference between the coral reefs associated with low and high anchoring intensities (group 1: $F=611.9$, df 1:5:847, $P<0.001$, group $2: F=7033.8$, df 1:5:720, $P<0.001)$. Coral reef photographs taken from sites associated with low anchoring intensity were given a higher health rating than those from sites with high levels of anchoring (Fig. 4). The health ratings of the coral reef sites provided by participants in group 1 were more conservative than those provided by participants in group 2, but overall the trends were similar between the participant groups (Fig. 4). Furthermore, there was remarkable similarity between the health ratings provided by each participant within each group (Cronbach reliability coefficient, group 1: alpha $=0.98$, group $2:$ alpha $=$ 0.98), suggesting that participants were consistent in their health judgments.

\section{Relationship between perceptual meanings and health judgments}

The mean health rating for each participant group was compared to the values from the evaluation, activity, and diversity dimensions. The three perceptual meanings explained $94.3 \%$ and $93.7 \%$ of the variation in the health ratings for group 1 and group 2, respectively (group 1: $r^{2}=0.943, F=139.4$, $\mathrm{df}=3: 22, P<0.001 ;$ group $2: r^{2}=0.937, F=124.2$, df $=3: 22, P<0.001)$. Health ratings provided by both participant groups were correlated with the evaluation dimension (Fig. 5). For group 1 participants, the evaluation dimension was the single best predictor of the judgment of health, and the activity and diversity dimensions did not explain any additional variance in the model; for group 1 participants: health judgment $=3.5+2.1$ (evaluation dimension). For group 2 participants, the evaluation dimension was correlated with the judgment of health, but activity and diversity dimensions improved the model, so for group 2, health judgment $=2.9+2.3$ (evaluation dimension) +1.2 (activity dimension) +1.1 (diversity dimension). However, the amount of variance explained by the activity and diversity components was minimal $(1.8 \%$ and $1.1 \%$, respectively). The evaluative dimension explained the most amount of variation in the photographs and correlated highly with the health judgment, suggesting that when people look at the environment they are assessing its health (Fig. 5).

\section{Environmental cues that described coral reef health}

The regression tree identified the relationship between the evaluation dimension, the five ecological measures, and the two remaining perceptual meanings. The regression tree analysis divided the coral reef photographs into two broad groups, depending on the percentage of coral damage present in the photographs (Fig. 6). Both groups of coral reef photographs were further subdivided, and the environmental cues that predicted the subdivision were different for each participant group. For participants from group 1, the low-damage photographs were divided according to the amount of activity present, and the highdamage photographs were divided based on the percent of branching corals present (Fig. 6A). For participants from group 2, the two groups of photographs were both subdivided according to the 
Fig. 2. Assessment of the coral reef sites associated with high and low intensities of anchoring using the five ecological measures. The graph shows the mean cover $( \pm \mathrm{SE})$ of each coral reef component. Results of MANOVA ( $F$ and $P$ values) are presented; degrees of freedom are 1:4:20. Note the difference scale on the $y$-axis.

Soft corals $(F=14.128) P=0.001$

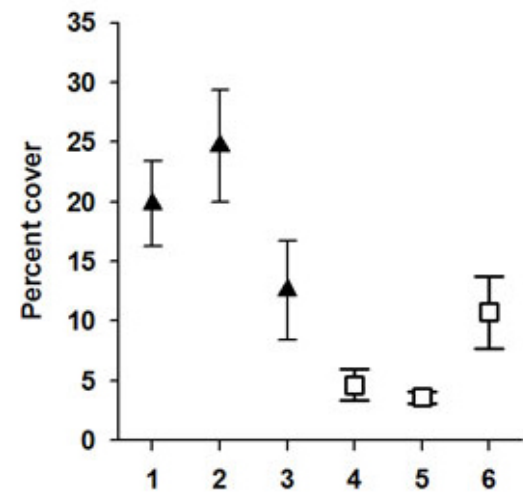

Branching corals $(F=3.390) P=0.080$

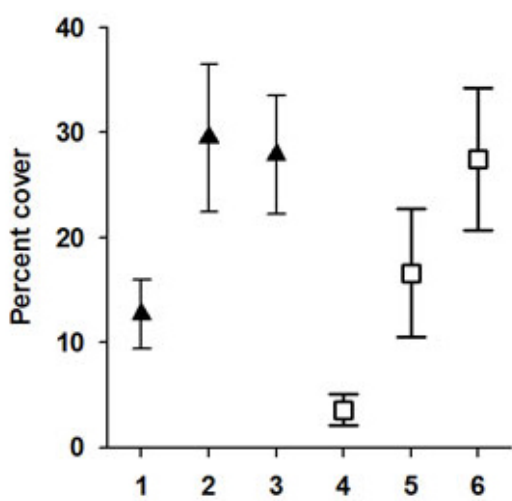

Massive corals $(F=0.653) P=0.529$

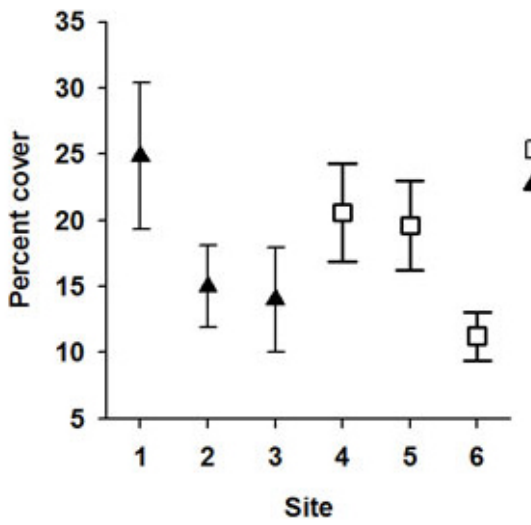

Fish $(F=4.337) P=0.050$

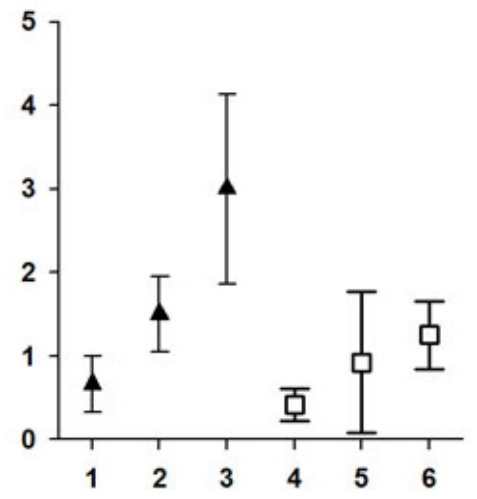

Damaged corals $(F=46.034) \mathrm{P}<0.001$

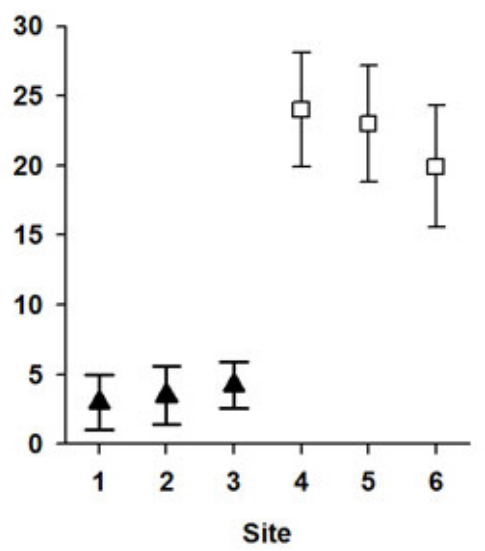

High anchoring

Low anchoring 
Fig. 3. Assessment of coral reef sites associated with high and low intensities of anchoring using the first two perceptual dimensions provided by participants who had a working association with coral reefs (A) and those who did not (B). The first perceptual meaning given to the coral reef environment was an evaluation, and the second was the amount of perceived activity. Each point represents one of the 26 photographs and where it was placed in the two-dimensional space described by the principal component analysis.

A

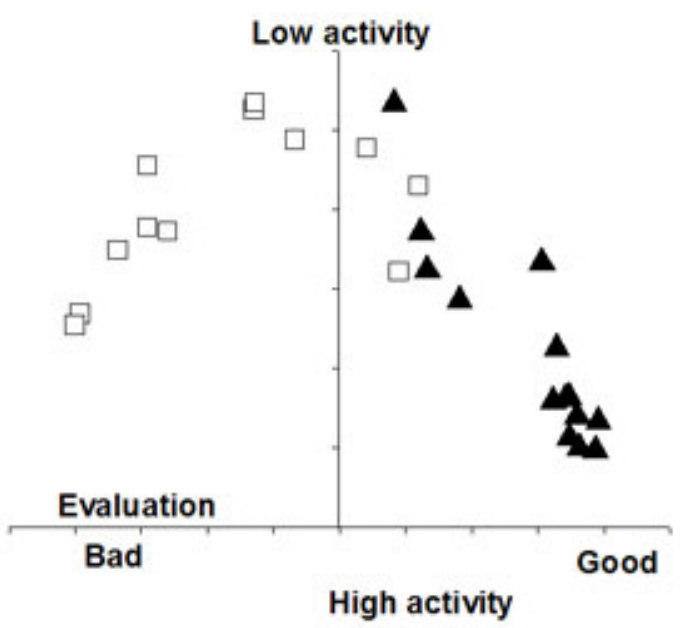

B

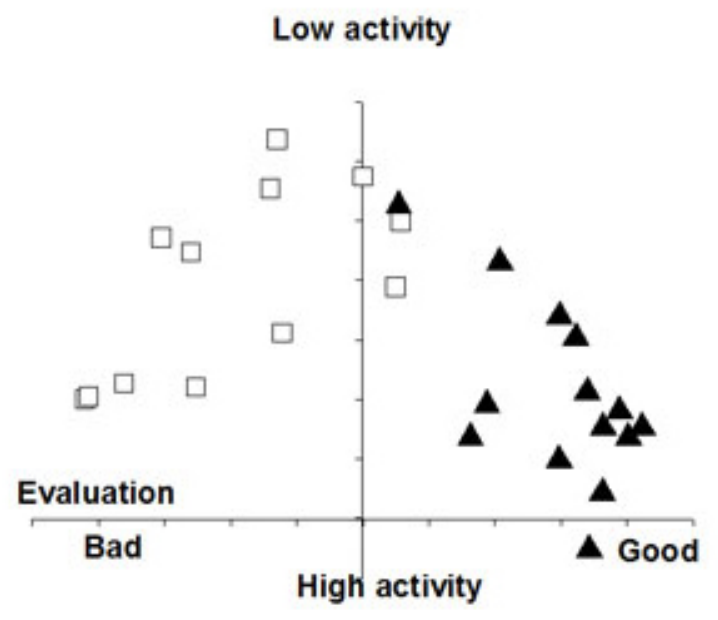

percentage of branching corals depicted (Fig. 6B). In both cases, the regression tree analysis separated the photographs into four health groups labeled A through D, and the trees constructed using the data provided by group 1 and 2 participants explained $88.3 \%$ and $85.2 \%$ of the variance, respectively.

The amount of damage was the environmental cue that explained the largest amount of variance in the health judgments of the coral reefs. For group 1 participants, photographs depicting less than $10.3 \%$ coral damage and a high perceived activity (group A) received a good evaluation, and the mean for group A was 0.7 (Fig. 7A). When the perceived activity dropped as it did in group B, so did the evaluation; the mean for group $\mathrm{B}$ was 0.3 (Fig. 7B). The lowest evaluation was given to group $\mathrm{C}$, in which the damage was greater than $10.3 \%$ and the cover of branching corals was less than $17.1 \%$; the group C mean was -0.6. Group D, in which the damage was high but the cover of branching coral was also high, was given a medium health rating with a mean of 0.1 . In group $\mathrm{C}$, the corals were mostly overturned (Fig. 7C), and in group D photographs, the corals had structural damage such as broken branches (Fig. 7D).

The regression tree developed using the evaluation dimension from group 2 participants showed that once again the amount of damage played the most important role in defining the four groups of photographs (Fig. 6B). Lower-level splits were caused by the amount of branching coral depicted in the photographs. The highest evaluation was provided when damage was low and the cover of branching corals was higher than $15.1 \%$ (group A mean $=0.688)$. When the cover of branching corals was less than $15.1 \%$, a lower evaluation was given, 
Fig. 4. The assessment of coral reef sites associated with high and low intensities of anchoring using the mean health ratings $( \pm \mathrm{SE})$ provided by participants who had a working association with coral reefs $(\mathrm{A})$ and those who did not (B).
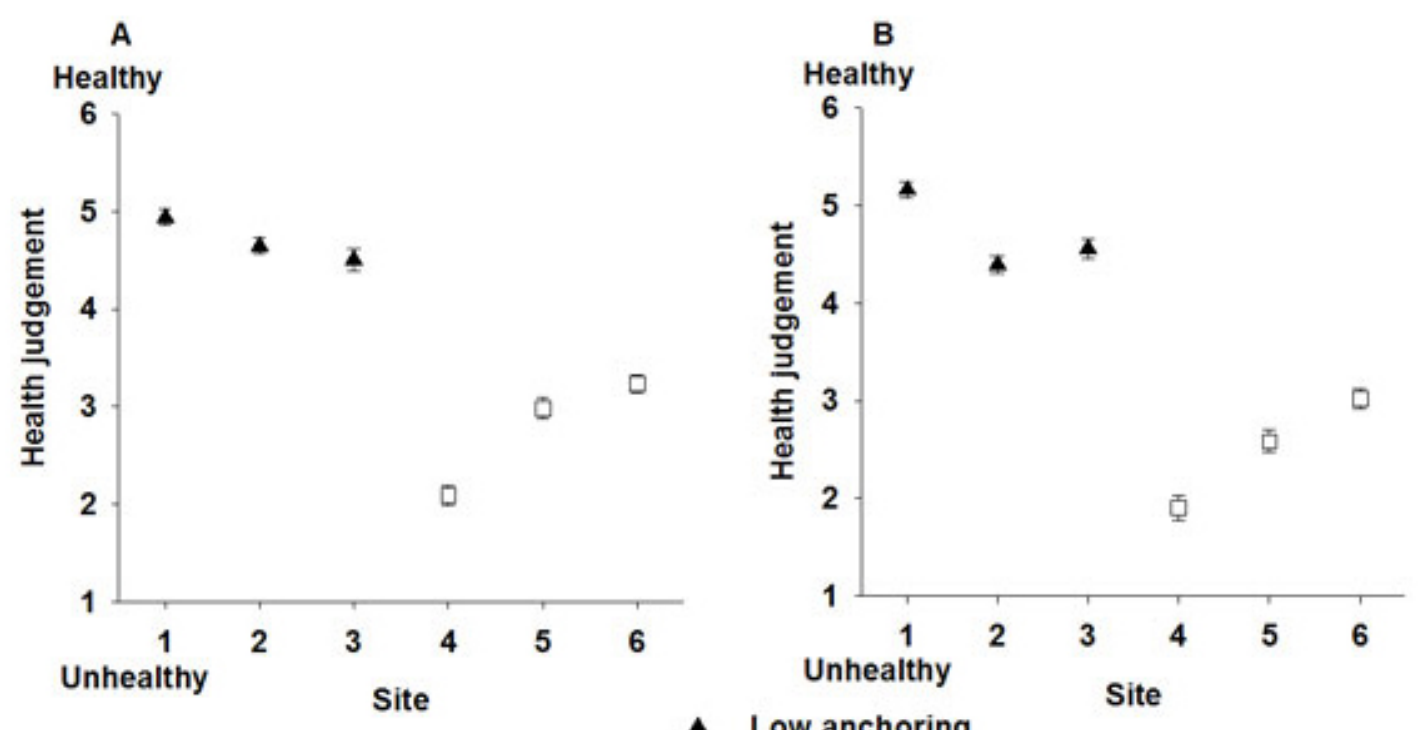

- Low anchoring

High anchoring

so that the group $\mathrm{B}$ mean was 0.4 (Fig. 6B). The lowest evaluation, i.e., the group $\mathrm{C}$ mean of -0.6 , was given for high damage and low cover of branching corals. High damage combined with higher coral cover received a higher health rating, yielding the group D mean of 0.01 (Fig. 7D).

In both regression trees, all but one of the photographs from the sites associated with high anchor intensities were on the high-damage side of the tree and therefore perceived as being in poor health. Conversely, all but one of the photographs from the sites associated with low anchoring intensities were on the low-damage side of the tree and perceived as healthy.

\section{DISCUSSION}

The correlation between the health judgment and the evaluation dimension demonstrates that people's most important assessment of the local environment, in terms of the amount of variation explained, is to judge its health. These judgments were linked to variations in coral condition. Therefore, in terms of environmental management, information on the condition of the environment could be provided by either ecological measures or people's perceptions. Kaplan and Kaplan (1989) have observed that people consistently prefer terrestrial landscapes that give them the opportunity to explore the environment but remain safe. From an evolutionary perspective, it is important for people to be able to identify environments that provide for their survival (Lackey 2003). In a terrestrial environment in which people have a long association with the landscape, it is reasonable to expect them to be able to distinguish between healthy and unhealthy environments. However, the underwater environment is not known in an evolutionary sense, and identifying a healthy underwater environment does not have immediate obvious survival benefits. The participants consistently described changes in the health of a relatively unknown environment, and their ability to describe this environment was not influenced by 
Fig. 5. The relationship of coral health ratings and the evaluation dimension of the perceptual meanings provided by participants who had a working association with coral reefs (A) and those who did not (B).

A

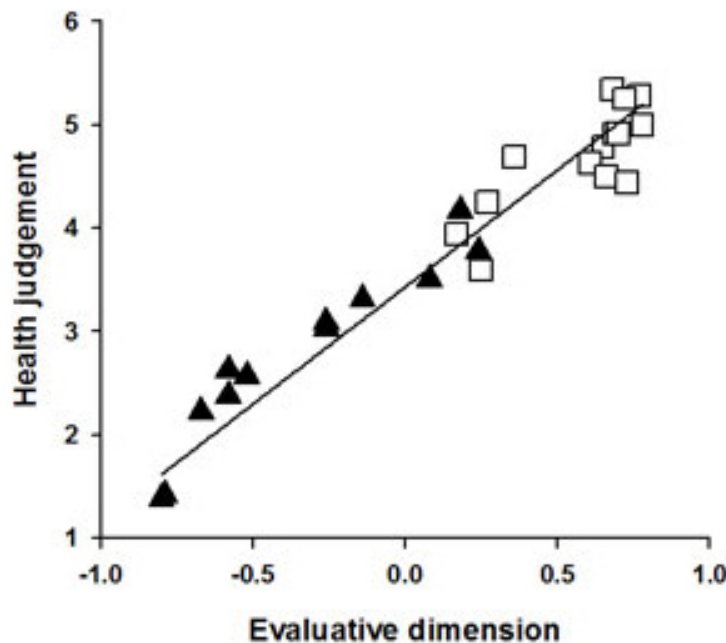

B

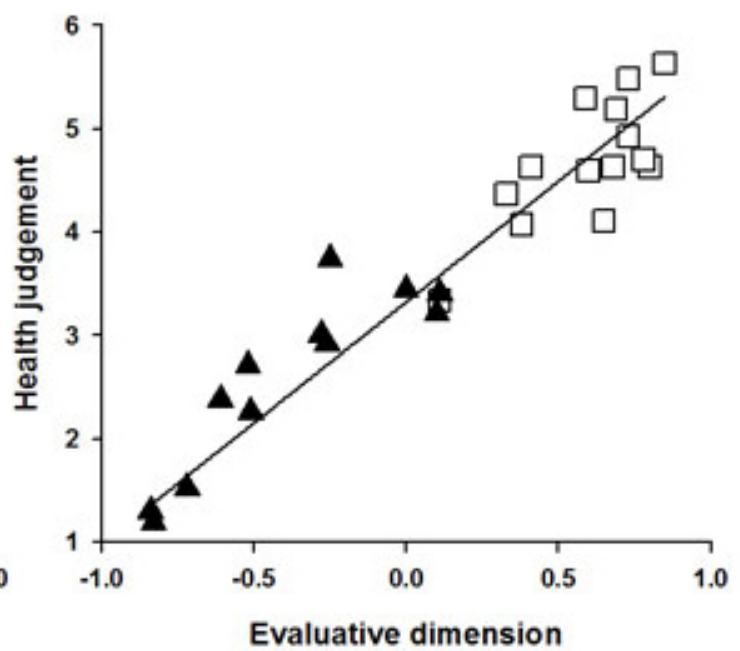

$\Delta$ High anchoring

Low anchoring

contemporary experiences, because both expert and lay groups provided similar descriptions. These two findings suggest that people may have an innate ability to determine the health of an environment and that the cues people use may cross ecological boundaries. However, the participants in our research study were from a restricted cultural background, so that including more people from a range of nationalities in a similar survey would help measure the extent of people's ability to assess the health of unfamiliar environments. It would also be worthwhile investigating whether or not people possess a generic set of cues for describing the health of the environment, no matter what that environment happens to be.

Although the terms used to interpret the condition of the environment differed, a consistent theme was provided by both expert opinion and local knowledge. Coral reefs associated with high levels of anchoring had lost condition, which was often described as increased damage and decreased coral cover or as a reduction in perceived value or health.
Similarly, other studies of local knowledge found that people had a good understanding of their environment (Berkes and Folke 2000, Olsson and Folke 2001, Zanetell and Knuth 2002, Gadgil et al. 2003). In some cases, important ecological knowledge such as knowledge of fish spawning aggregations, relationships between trophic levels, changes in sea-ice patterns, and facilitative activities of co-existing organisms (Hill et al. 1999, MacKinson 2001, Johnson and Graber 2002, Robertson and McGee 2003, Camilleri 2004) is only available from local communities.

Combining information from both expert and lay communities in environmental management generally provides a more complete picture of environmental circumstances than does information collected from one perspective alone (Schaeffer 1996, Boulton 1999, Norris and Thoms 1999). In this coral reef case study, the ecological measures describe changes in the amount of damage and the cover of branching and soft corals associated with anchoring, and the perceptual meanings indicate 
Fig. 6. The relationship of the evaluation dimension to the five ecological measures and the two subjective descriptions provided by the regression tree analysis for participants who had a working association with coral reefs (A) and those who did not (B). The values of the predicted variables for the ecological measures provided on the tree are the percent cover and, for the perceptual meanings, the value from the component matrix. The regression tree analysis determined four groups of photographs $(\mathrm{A}, \mathrm{B}, \mathrm{C}$, and $\mathrm{D})$, and the mean evaluation score $(\mathrm{E})$ for each group is provided.
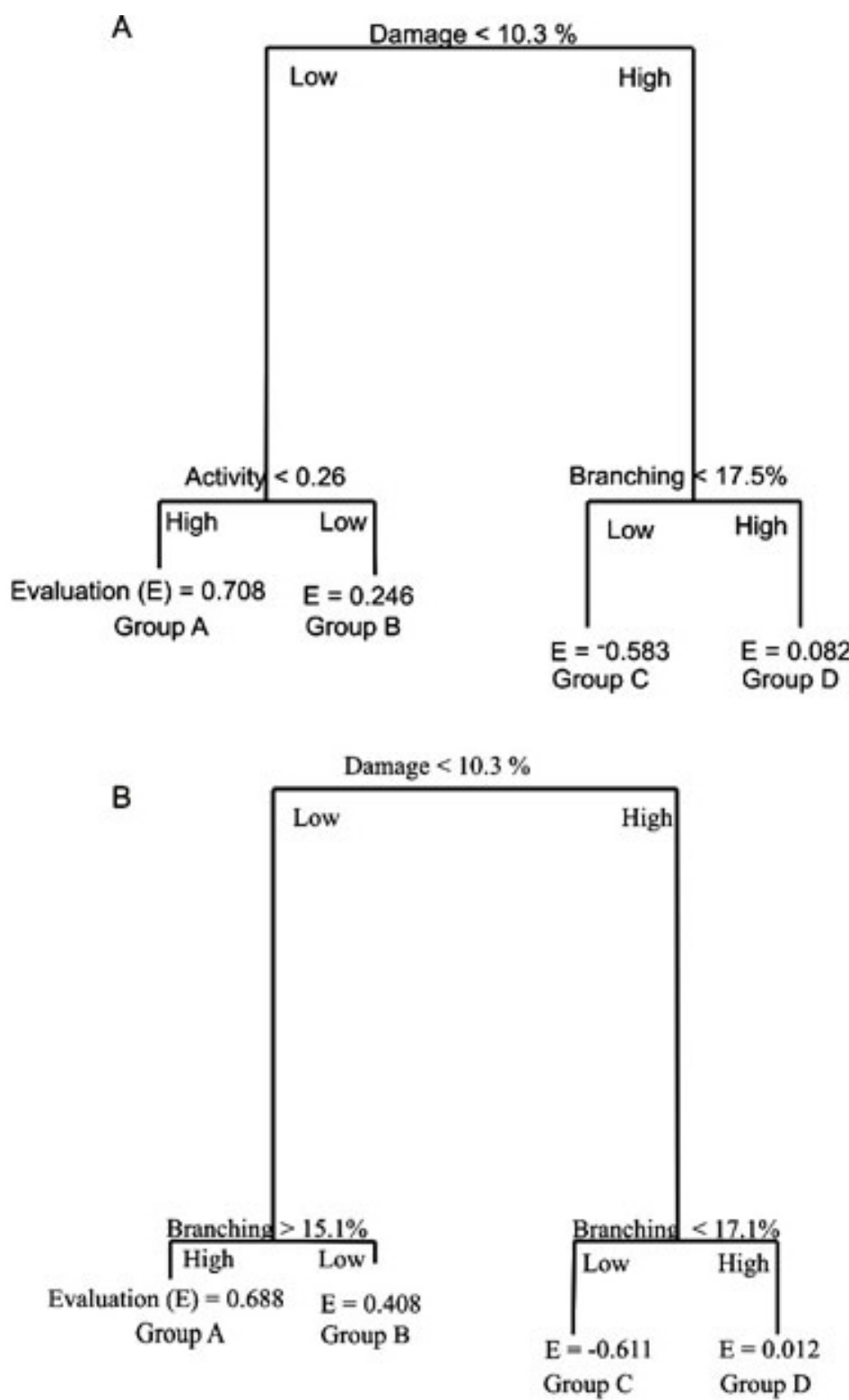
Fig. 7. Two representative photographs for each health group identified by the regression tree analysis. Photographs A1 and A2 from health group depict low damage and high branching corals or perceived activity. Photographs B1 and B2 from health group B depict low damage and low cover of branching corals or perceived activity. Photographs $\mathrm{C} 1$ and $\mathrm{C} 2$ from health group $\mathrm{C}$ depict high damage and low cover of branching corals; note also the overturned corals. Photographs D1 and D2 from health group D depict high damage and higher cover of branching corals; note that the damage consists of broken branches.
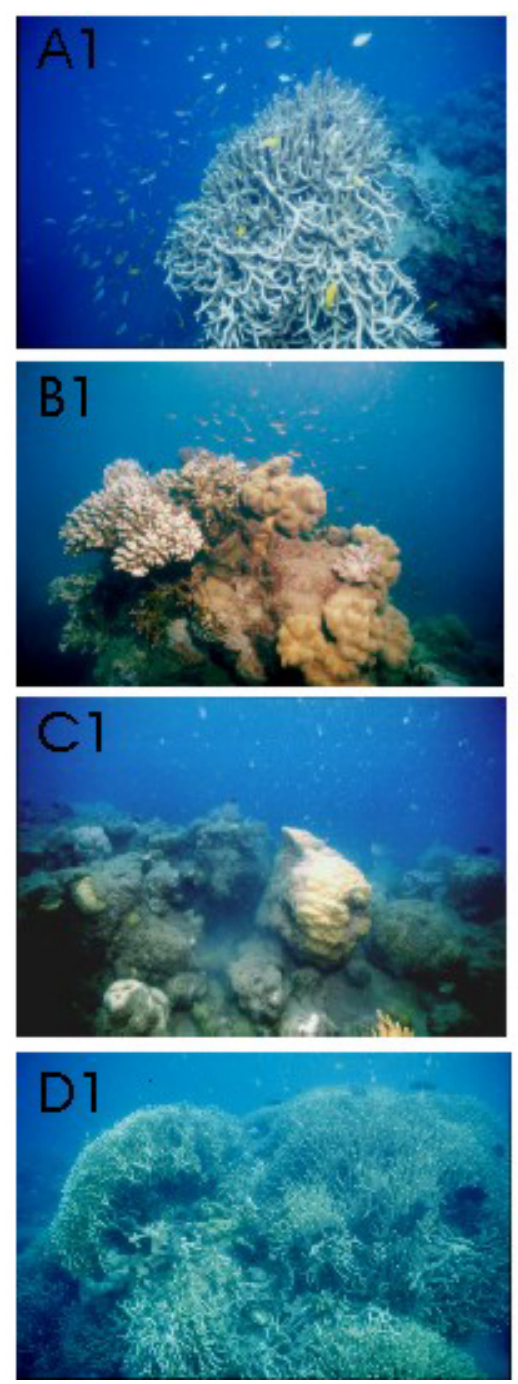

that the coral reefs had lost their visual quality. By linking these measures, management can say that, if the anchoring becomes too intense, the amounts of branching and soft corals will decline and people will no longer find the coral reef healthy. Given that people value the coral reef environment, a statement in these terms by a management agency may
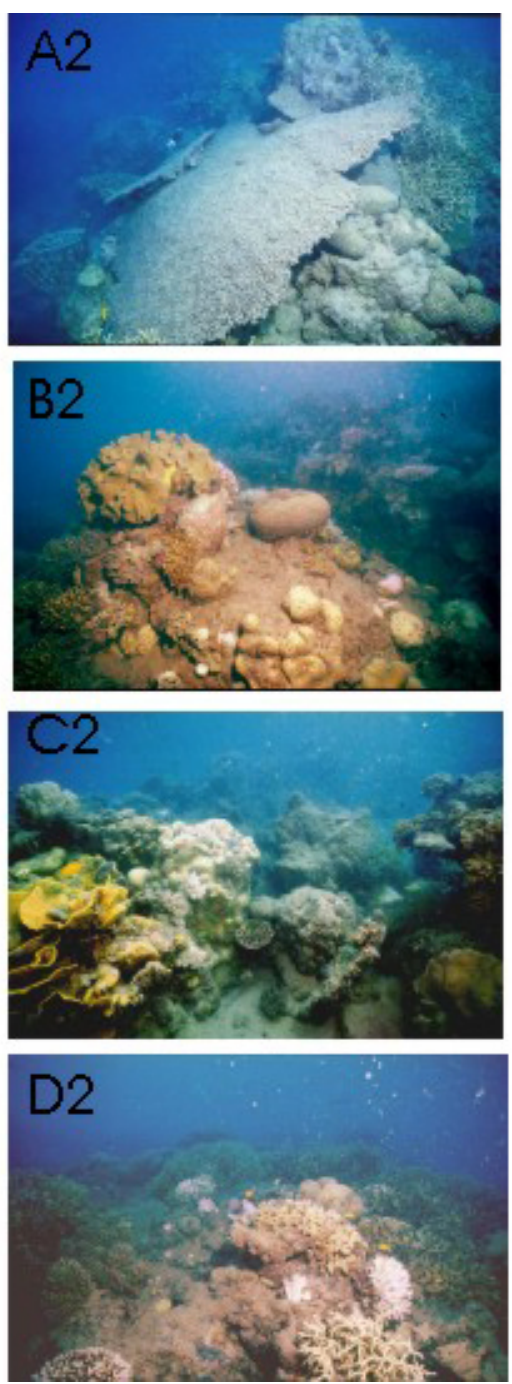

motivate people to change their activity and provide a reason for implementing new management policies.

One of the difficulties in environmental management is pinpointing when the environmental condition changes (Bunn et al. 1999, Fairweather 
1999, Karr 1999, Hilty and Merenlender 2000). Identifying environmental cues to assess the condition of an environment by linking judgments of health with ecological and perceptual measures reinforces the dual role of societal values and biophysical elements, which is important in management decisions. This emphasis is rarely considered in the development of environmental cues, which are commonly developed from an ecological perspective only (Done 1992). In the coral reef case study, participants' health judgments were affected primarily by the level of damage and then by the cover of branching corals or perceived activity, making these variables important environmental cues to assess the effects of anchoring. The regression tree analysis of these reefs predicts that, when coral damage rises above $10.3 \%$ of the area under examination, the health of the coral reef has declined. A further decline in the health of the coral reef will occur if the damage is coupled with a loss of coral cover, particularly of corals with a branching morphology. Therefore, if the management agency identifies areas in the local Whitsundays region with damage above $10.3 \%$, mitigation strategies should be implemented. Whether these values can be extrapolated across the entire Great Barrier Reef needs further investigation.

Two levels of health ratings were given for the highdamage photographs. By reviewing the types of damage depicted in the photographs, it was found that the lowest health rating was associated with overturned colonies and a medium health rating was associated with structural types of damage, such as breakage and fragmentation. The difference between the two health ratings is potentially associated with the participants' perception of the severity of the two types of damage. Overturned colonies suggest a high level of impact and an extensive recovery time (Marshall 2000b). In comparison, breaks to branching coral colonies are frequent and the time to recover from the loss of a coral branch is less (Smith and Hughes 1999). The fragments that are generated by physical damage have the ability to reattach to the substratum and grow, although the survival rate of fragments is lower compared with that of an intact colony (Rapport et al. 1998, Whitford et al. 1999). Resilience and recovery are important factors influencing the health of a system (Ulanowicz 2000 ), and the ability of corals to recover from damage is a criterion that people are potentially using in their health judgments.
Reef health was judged to be good in coral reef photographs that had low coral damage and high activity or a high cover of branching coral. The activity dimension, which is important to participants with a working association with coral reefs, was related to the whole system; it included components such as the numbers of fish, the types and shapes of corals, and perceived movement by, e.g., feeding coral polyps. The use of the activity dimension suggests that these participants were interested not only in what type of and how much coral was present, but also in how the system appeared to be functioning. Measuring the condition of the whole landscape is an important feature identified by other studies, e.g., the multimetric index of biological integrity as described by Karr (2000) and the model for describing resilience by estimating intrasystem exchanges such as prey/ predator relationships, as described by Ulanowicz (2000). The amount of branching corals was the second most important environmental cue used by lay participants and may relate to images portrayed in the media or the perception that, because branching corals look fragile, the environment is healthy if they are present and intact.

One critical issue in the management of human activity is being able to determine whether the effect of these activities is good or bad for the health or integrity of the environment (Gasteyer and Flora 2000, Blann et al. 2003). The results show that it is possible to identify environmental cues that describe changes to the state of the coral reef environment. Furthermore, these environmental cues can be identified from either an ecological or a social perspective. Developing environmental cues from a social perspective is advantageous because changes in the environment are described in terms that people comprehend and may motivate a change in their behavior to sustain the health of the environment. Improvement in community participation has occurred when environmental condition was measured in terms that people could understand rather than technical terms that carried no local meaning (Carr 2002).

Apart from obtaining a large amount of relevant information, involving people in management decisions is good for the well-being of the community (Ostrom et al. 1999). Community ideas and organizations increase the complexity of management structures, thereby increasing flexibility and, in some cases, the speed of management responses (Michaelidou et al. 2002). Involving the 
community in environmental management maintains its values and traditions, reinforces community identity, promotes stability, and enhances the ability of the community to adapt to new situations (Machlis 1992, Margoluis and Salafsky 1998). Because about 1.5 million people visit the Great Barrier Reef per year, a health judgment provided by these people would provide information on the coral condition over an extensive area.

Fitzsimmons (2003) argued that the ecosystem health concept was "nebulous and uncertain" and did not provide a "cogent foundation for government action," but did not conduct any measurements to identify whether people use the concept. However, my research suggests that, for coral reef environments, people's vision of a healthy environment is consistent and reliable. Descriptions of the environment using either experiential or scientific methods provide usable information about the condition of the environment. Participants were able to detect changes in coral reef condition that altered their perception of the coral reef environment. Because the environment lost value, changing from one that was healthy and evaluated highly to one that was unhealthy and evaluated poorly, people may be motivated to change their behavior to reverse the declining trend and promote a healthy coral reef.

Responses to this article can be read online at: http://www.ecologyandsociety.org/voll4/iss2/art28/ responses/

\section{Acknowledgments:}

Thanks to my supervisors Vicki Harriott, Mark Fenton, and Peter Valentine for their support of the research and encouragement to conduct a multidisciplinary research project. The research would not have been possible without the survey participants or numerous field volunteers. This research was funded by the CRC Reef Research Centre, School of Tropical Environment Studies and Geography, Great Barrier Reef Marine Park Authority, and Queensland Smart State Funding. Logistical support was provided by Queensland Parks and Wildlife Service and Hayman Island Resort. Thanks to Rob Edwards for comments on the manuscript and Forest Rohwer for providing a postdoctoral position.

\section{LITERATURE CITED}

\author{
Bellamy, J. A., G. T. McDonald, G. J. Syme, and
} J. E. Butterworth. 1999. Evaluating integrated resource management. Society and Natural Resources 12:337-353.

Berkes, F., and C. Folke, editors. 2000. Linking social and ecological systems: management practices and social mechanisms for building resilience. Cambridge University Press, Cambridge, UK.

Best, B., and A. Bornbusch, editors. 2001. Global trade and consumer choices: coral reefs in crisis. Symposium of the 2001 Annual Meeting of the American Association for the Advancement of Science (San Francisco 2001). American Association for the Advancement of Science, Washington, D.C., USA. Available online at: http:/ /www.aaas.org/international/africa/coralreefs/Coral Reefs. pdf.

Blann, K., S. Light, and J. A. Musumeci. 2003. Facing the adaptive challenge: practitioners' insight from negotiating resources crises in Minnesota. Pages 210-240 in F. Berkes, J. Colding, and C. Folke, editors. Navigating social-ecological systems: building resilience for complexity and change. Cambridge University Press, Cambridge, UK.

Boulton, A. J. 1999. An overview of river health assessment: philosophies, practice, problems and prognosis. Freshwater Biology 41:469-479.

Brock, W.A., and R. C. Carpenter. 2007. Panaceas and diversification of environmental policy. Proceedings of the National Academy of Sciences of the United States of America 104:15206-15211.

Bunn, S. E., P. M. Davies, and T. D. Mosisch. 1999. Ecosystem measures of river health and their response to riparian and catchment degradation. Freshwater Biology 41:333-345.

Burroughs, R. 1999. When stakeholders choose: process, knowledge, and motivation in water quality decisions. Society and Natural Resources 12:797-809.

Camilleri, M. 2004. From the inside looking out: knowledge, justice and modernity in the assessment of St. Julian's environmental capacity. Local Environment 9:45-63. 
Carr, A. 2002. Grass roots and green tape: principles and practices of environmental stewardship. Federation Press, Sydney, Australia.

Cousins, J. A., J. Evans, and J. Saddler. 2009. Selling conservation? Scientific legitimacy and the commodification of conservation tourism. Ecology and Society 14(1):32. [online] URL: http://www.ec ologyandsociety.org/vol14/iss1/art32.

De'ath, G. 2002. Multivariate regression trees: a new technique for modeling species-environment relationships. Ecology 83:1105-1117.

De\&\#8217'ath, G., and K. E. Fabricius. 2000. Classification and regression trees: a powerful yet simple technique for the analysis of complex ecological data. Ecology 81:3178-3192.

Dinsdale, E. A., and D. M. Fenton. 2006. Assessing coral reef condition: eliciting community meanings. Society and Natural Resources 19:239-258.

Dinsdale, E. A., and V. J. Harriott. 2004. Assessing anchor damage on coral reefs: a case study in the selection of environmental indicators. Environmental Management 33:126-139.

Done, T. J. 1992. Effects of tropical cyclone waves on ecological and geomorphological structure on the Great Barrier Reef. Continental Shelf Research 12:859-872.

Done, T. J. 1995. Ecological criteria for evaluating coral reefs and their implication for managers and researches. Coral Reefs 14:183-192.

Endter-Wada, J., D. Blahna, R. Krannich, and M. Brunson. 1998. A framework for understanding social science contributions to ecosystem management. Ecological Applications 8:891-904.

Failing, L., G. Horn, and P. Higging. 2004. Using expert judgement and stakeholder values to evaluate adaptive management options. Ecology and Society 9(1):13. [online] URL: http://www.ecologyandsociety. org/vol9/iss1/art13.

Fairweather, P. G. 1999. Determining the "health" of estuaries: priorities for ecological research. Australian Journal of Ecology 24:441-451.
Fitzsimmons, E. A. 2003. Ecosystem health: a flawed base for federal regulation and landuse management. Pages 187-197 in A. B. Damania, editor. Managing for healthy ecosystems. Lewis, Boca Raton, Florida, USA.

Fryirs, K., and G. J. Brierley. 2009. Naturalness and place in river rehabilitation. Ecology and Society 14(1):20. [online] URL: http://www.ecolog yandsociety.org/vol14/iss1/art20.

Gadgil, M., P. Olsson, F. Berkes, and C. Folke. 2003. The role of local ecological knowledge in ecosystem management. Pages 189-209 in F. Berkes, J. Colding, and C. Folke, editors. Navigating social-ecological systems: building resilience for complexity and change. Cambridge University Press, Cambridge, UK.

Gasteyer, S. P., and C. B. Flora. 2000. Measuring ppm with tennis shoes: science and locally meaningful indicators of environmental quality. Society and Natural Resources 13:589-597.

Great Barrier Reef Marine Park Authority (GBRMPA). 1999. Whitsundays Plan of Management. GBRMPA, Townsville, Australia.

Great Barrier Reef Marine Park Authority (GBRMPA). 2009. Whitsundays Plan of Management area total visitors by year. GBRMPA, Townsville, Australia.

Gunderson, L., C. S. Holling, and S. Light, editors. 1995. Barriers and bridges to the renewal of ecosystems and institutions. Columbia University Press, New York, New York, USA.

Harriott, V. J. 2002. Marine tourism impacts and their management on the Great Barrier Reef. CRC Reef Research Centre Technical Report No. 46. CRC Reef Research Centre, Townsville, Australia.

Hill, R., A. Baird, and D. Buchanan. 1999. Aborigines and fire in the wet tropics of Queensland, Australia: ecosystem management across cultures. Society and Natural Resources 12:205-223.

Hilty, J., and A. Merenlender. 2000. Faunal indicator taxa selection for monitoring ecosystem health. Biological Conservation 92:185-197.

Holling, C. S., F. Berkes, and C. Folke. 2000. Science, sustainability and resource management. 
Pages 342-362 in F. Berkes and C. Folke, editors. Linking social and ecological systems: management practices and social mechanisms for building resilience. Cambridge University Press, Cambridge, UK.

Hull, R. B., D. Richert, E. Seekamp, D. Robertson, and G. J. Buhyoff. 2003. Understanding of environmental quality: ambiguities and values held by environmental professionals. Environmental Management 31:1-13.

Huntington, H. P., P. K. Brown-Schwalenberg, K. J. Frost, M. E. Fernandez-Gimenez, and D. W. Norton. 2002. Observations on the workshop as a means of improving communication between holders of traditional and scientific knowledge. Environmental Management 30:778-792.

Hutchings, P. 2004. Editorial. Marine Pollution Bulletin 50:1-4.

Johnson, S. E., and B. E. Graber. 2002. Enlisting the social sciences in decisions about dam removal. Bioscience 52:731-738.

Kaplan, R., and S. Kaplan. 1989. The experience of nature: a psychological perspective. Cambridge University Press, Cambridge, UK.

Karr, J. R. 1999. Defining and measuring river health. Freshwater Biology 41:221-234.

Karr, J. R. 2000. Health, integrity and biological assessment: the importance of measuring whole things. Pages 209-226 in D. Pimentel, L. Westra, and R. F. Noss, editors. Ecological integrity: integrating environment, conservation, and health. Island Press, Washington, D.C., USA.

Lackey, R. T. 2003. Appropriate use of ecosystem health and normative science in ecological policy. Pages 175-186 in D. J. Rapport, W. L. Lasley, D. E. Rolston, N. O. Nielsen, C. O. Qualset, and A. B. Damania, editors. Managing for healthy ecosystems. Lewis, Boca Raton, Florida, USA.

Lele, S., and R. B. Norgaard. 1996. Sustainability and the scientist's burden. Conservation Biology 10:354-365.

Machlis, G. E. 1992. The contribution of sociology to biodiversity research and management. Biological Conservation 62:161-170.
MacKinson, S. 2001. Integrating local and scientific knowledge: an example in fisheries science. Environmental Management 27:533-545.

Macnaghten, P., and J. Urry. 1998. Contested natures: theory, culture and society. Sage, London, UK.

Malcolm, H. 1998. Immediate benefits of establishing a "no anchoring area": a case study at two popular anchorages in the Whitsundays. Technical report to the Queensland Department of Environment and Heritage. Queensland Department of Environment and Heritage, Brisbane, Australia.

Margoluis, R., and N. Salafsky. 1998. Measures of success: designing, managing and monitoring conservation and development projects. Island Press, Washington, D.C., USA.

Marshall, P.A. 2000a. Physical disturbance in reef corals: biology, ecology and management implications. Dissertation. James Cook University, Townsville, Australia.

Marshall, P. A. 2000b. Skeletal damage in reef corals: relating resistance to coral morphology. Marine Ecology Progress Series 200:177-189.

McNeely, J. A., editor. 1995. Expanding partnerships in conservation. Island Press, Washington, D.C., USA.

Michaelidou, M., D. J. Decker, and J. P. Lassoie. 2002. The interdependence of ecosystem and community viability: a theoretical framework to guide research and application. Society and Natural Resources 15:599-616.

Norris, R. H., and M. C. Thoms. 1999. What is river health? Freshwater Biology 41:197-209.

O'Flaherty, R. M., I. J. Davidson-Hunt, and M. Manseau. 2008. Indigenous knowledge and values in planning for sustainable forestry: Pikangikum First Nation and the Whitefeather Forest Initiative. Ecology and Society 13(1):6. [online] URL: http:// www.ecologyandsociety.org/vol13/iss1/art6.

Olsson, P., and C. Folke. 2001. Local ecological knowledge and institutional dynamics for ecosystem management: a study of Lake Racken watershed, Sweden. Ecosystems 4:85-104. 
Ostrom, E., J. Burger, C. B. Field, R. B. Norgaard, and D. Policansky. 1999. Revisiting the commons: local lessons, global challenges. Science 284:278-282.

Policansky, D. 1998. Science and decision making for water resources. Ecological Applications 8:610-618.

Rapport, D. J., R. Costanza, and A. J. McMichael. 1998. Assessing ecosystem health. Trends in Evolution and Ecology 13:397-402.

Robertson, D. P., and R. B. Hull. 2001. Beyond biology: towards a more public ecology for conservation. Conservation Biology 15:970-979.

Robertson, H. A., and T. K. McGee. 2003. Applying local knowledge: the contribution of oral history to wetland rehabilitation at Kanyapella Basin, Australia. Journal of Environmental Management 69:275-287.

Robertson, M., P. Nichols, P. Horwitz, K. Bradby, and D. MacKintosh. 2000. Environmental narratives and the need for multiple perspectives to restore degraded landscapes in Australia. Ecosystem Health 6:119-133.

Ross, N., J. Eyles, D. Cole, and A. Iannantuono. 1997. The ecosystem health metaphor in science and policy. Canadian Geographer 41:114-127.

Schaeffer, D. J. 1996. Diagnosing ecosystem health. Ecotoxicology and Environmental Safety 34:18-34.

Slocombe, D. S. 1998. Defining goals and criteria for ecosystem-based management. Environmental Management 22:483-493.

Smith, L. D., and T. P. Hughes. 1999. An experimental assessment of survival, re-attachment and fecundity of coral fragments. Journal of Experimental Marine Biology and Ecology 235:147-164.

Song, S. J., and R. M. M'Gonigle. 2001. Science, power, and system dynamics: the political economy of conservation biology. Conservation Biology 15:980-989.
Tress, D. M. 2002. Reuniting science and value in the natural environment. Pages 213-221 in T. M. Roberson and L. Westra, editors. Thinking about the environment: our debt to the classical and medieval past. Lexington Books, Lanham, Maryland, USA.

Ulanowicz, R. E. 2000. Towards the measurement of ecological integrity. Pages 99-113 in D. Pimentel, L. Westra, and R. F. Noss, editors. Ecological integrity: integrating environment, conservation, and health. Island Press, Washington, D.C., USA.

Ura, K. 2003. Gambling for sustainability-local institutions for pasture management in Bhutan. Pages 697-701 in D. J. Rapport, W. L. Lasley, D. E. Rolston, N. O. Nielsen, C. O. Qualset, and A. B. Damania, editors. Managing for healthy ecosystems. Lewis, Boca Raton, Florida, USA.

Whitford, W. G., D. J. Rapport, and A. G. de Soyza. 1999. Using resistance and resilience measurements for "fitness" tests in ecosystem health. Journal of Environmental Management 57:21-29.

Zanetell, B.A., and B.A. Knuth. 2002. Knowledge partnerships: rapid rural appraisal's role in catalyzing community-based management in Venezuela. Society and Natural Resources 15:805-825. 